\title{
Herpes zoster ophthalmicus complicated by encephalitis
}

\author{
Snigdha Jain MBBS, Rohan Khera MBBS
}

Competing interests:

None declared.

This article has been peer reviewed.

The authors have obtained patient consent.

Affiliation: Department of Internal Medicine,

University of Iowa Carver College of Medicine, Iowa City, Iowa

\section{Correspondence to:}

Snigdha Jain,

snigdha-jain@uiowa.edu;

Rohan Khera,

rohan-khera@uiowa.edu

CMAJ 2016. DOI:10.1503 /cmaj.150342
$\mathrm{A}$ 56-year-old woman who was otherwise healthy presented with a one-week history of right eye pain, headache and a rash on her forehead. On physical examination, she had a temperature of $38^{\circ} \mathrm{C}$ and a dermatomal maculopapular rash without any vesicles in the V1 distribution extending to the tip of her nose (Figure 1). Examination of the right eye revealed proptosis, conjunctival injection, visual acuity of $20 / 25$, and external ophthalmoplegia without evidence of uveitis or retinitis. Examination of the left eye was normal. The rash was suspicious for herpes zoster and was biopsied. The patient was confused, but there were no focal deficits on neurologic examination.

Lumbar puncture was performed to evaluate her altered mental status, and cerebrospinal fluid analysis showed an elevated total protein level of 1.2 (normal < 0.45) g/L, a glucose level of 3.1 (normal 2.2-4.2) $\mathrm{mmol} / \mathrm{L}$ and lymphocytic pleocytosis with 0.57 (normal < 0.01$) \times 10^{9} / \mathrm{L}$ lymphocytes. Magnetic resonance imaging of the brain showed findings consistent with posterior lobe encephalitis (Appendices 1 and 2, available at www.cmaj.ca/lookup/suppl/doi:10.1503/ cmaj.150342/-/DC1). Polymerase chain reaction of a biopsy of the skin lesions and cerebrospinal fluid were positive for varicella-zoster virus DNA. She tested negative for HIV, but other tests to determine immunocompetence were not performed. She was given intravenous acyclovir $650 \mathrm{mg}(10 \mathrm{mg} / \mathrm{kg})$ every eight hours for 10 days, and was discharged home. On the most recent follow-up, five months after discharge, she was doing well without any complications of postherpetic neuralgia or vision loss.

Encephalitis is a known complication of herpes zoster, described in both immunocompromised and, rarely, immunocompetent patients. ${ }^{1,2}$ About $9 \%$ of all patients with herpes zoster have ocular involvement, but the proportion of cases complicated by encephalitis is unknown. ${ }^{3}$ Clinical mani-

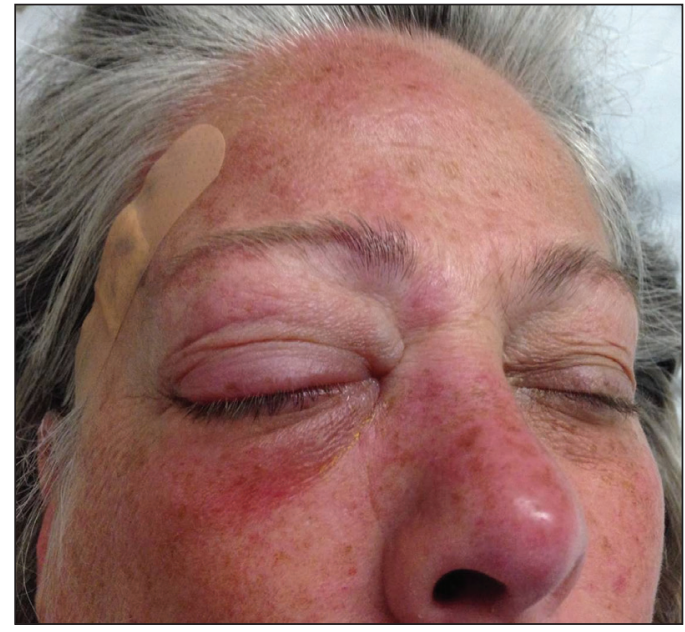

Figure 1: Photograph showing dermatomal maculopapular rash in the V1 distribution on the face of a 56-year-old woman. The rash involves the tip of the nose, suggesting higher chances of ocular involvement. The adhesive bandage is placed at the site of the skin biopsy; there are no ulcerations or vesicles underneath.

festations include fever, headache, delirium and focal neurologic signs. ${ }^{1,4}$ Polymerase chain reaction testing of cerebrospinal fluid for varicellazoster virus DNA has a sensitivity of $80 \%-95 \%$ and a specificity of greater than $95 \% .2,5$ Recommended treatment includes intravenous acyclovir for 10-14 days, but the ideal duration and adjunctive use of steroids are not established. Mortality is about $10 \%$ regardless of treatment. ${ }^{2,4}$

\section{References}

1. Appelbaum E, Kreps SI, Sunshine A. Herpes zoster encephalitis. Am J Med 1962;32:25-31.

2. Tunkel AR, Glaser CA, Bloch KC, et al. The management of encephalitis: clinical practice guidelines by the Infectious Diseases Society of America. Clin Infect Dis 2008;47:303-27.

3. Yawn BP, Wollan PC, St Sauver JL, et al. Herpes zoster eye complications: rates and trends. Mayo Clin Proc 2013;88:562-70.

4. Dworkin RH, Johnson RW, Breuer J, et al. Recommendations for the management of herpes zoster. Clin Infect Dis 2007;44(Suppl 1):S1-26.

5. Debiasi RL, Tyler KL. Molecular methods for diagnosis of viral encephalitis. Clin Microbiol Rev 2004;17:903-25. 